\title{
Monetary Policy Experiments in an Agent-Based Macroeconomic Model
}

\author{
Elder Mauricio Silva1, Guilherme Moura1,2, Sergio Da Silva ${ }^{1,2,3^{*}}$ \\ ${ }^{1}$ Graduate Program in Economics, Federal University of Santa Catarina, Florianopolis, Brazil \\ ${ }^{2}$ Department of Economics, Federal University of Santa Catarina, Florianopolis, Brazil \\ ${ }^{3}$ Graduate Program in Economics, Federal University of Espirito Santo, Vitoria, Brazil \\ Email: *professorsergiodasilva@gmail.com
}

How to cite this paper: Silva, E.M. Moura, G. and Da Silva, S. (2021) Monetary Policy Experiments in an Agent-Based Macroeconomic Model. Open Access Library Journal, 8: e7471.

https://doi.org/10.4236/oalib.1107471

Received: April 29, 2021

Accepted: May 23, 2021

Published: May 26, 2021

Copyright (C) 2021 by author(s) and Open Access Library Inc.

This work is licensed under the Creative

Commons Attribution International

License (CC BY 4.0)

http://creativecommons.org/licenses/by/4.0/

\begin{abstract}
We consider an interbank market and a central bank in an agent-based macroeconomic model with credit and capital to evaluate the effects of monetary policies-conventional and quantitative easing. We find quantitative easing outperforms Taylor's rule-style policies in smoothing out the business cycle.
\end{abstract}

\section{Subject Areas}

Monetary Economics

\section{Keywords}

Agent-Based Macroeconomic Model, Monetary Policy, Financial Crises, Taylor's Rule, Quantitative Easing, Business Cycles

\section{Introduction}

This work builds on an agent-based macroeconomic model with capital and credit (Assenza et al. 2015) [1] to further consider an interbank market and a central bank. Our goal is to evaluate the role conventional and unconventional monetary policies play in the extended model. We simulate central bank responses to fluctuations in real GDP and unemployment by considering eight experiments related to four conventional policies and four quantitative-easing policies.

The model features capital goods' firms ( $K$-firms), consumer goods' firms ( $C$-firms) and a supply chain. Firms of all types resort to bank loans to meet their financial needs. There is a two-way feedback between firms and markets, and sometimes credit crunch followed by recovery emerge. Inserting the interbank market and the central bank does not change significantly the dynamics of 
the original model of Assenza et al. (2015) [1].

The importance of considering an interbank market can be appreciated in Gertler et al. (2016) [2]. The debate on how to best model financial crisis has been reopened after the 2008 crisis. Bernanke and Gertler (1989) [3] and Kyotaki and Moore (1997) [4] had already pointed to the interbank market as a source of financial problems with real output effects. Balance sheets of the financial sector tend to be procyclical, which means economic growth follows a credit supply expansion and vice versa, and such moves become amplified through positive feedback loops. Gertler et al. (2016) [2] further add that during a financial crisis wholesale banks play a major role. Wholesale banks hold debts with other financial institutions rather than with households and become highly leveraged in short-term debts on the eve of a financial crisis. Retail banks also play a role as they collect deposits from households and offer loans to firms and the interbank market. Thus, a full-blown interbank market is key for modeling the transmission of a financial crisis to the real economy.

To consider monetary policy experiments in our extended model, we need to endogenize the base interest rate that is exogenous in the original model. Here, we assume the central bank chooses the interest rate according to Taylor's rule (Taylor 1993) [5]. The base interest rate affects the interbank interest rate and is considered by the banks when offering loans to the firms. By Taylor's rule, when the output gap widens, the central bank reduces the interest rate, but increases it when inflation rises.

Central banks' responses using the parameters from Taylor's rule may change over time. Taylor's original parameter configuration seems to work well for his period of analysis of the American economy, but not for the preceding periods and the post-1993 period (Clarida et al. 1999) [6]. For example, the central bank reaction function in the Volcker-Greenspan era is more sensitive to changes in inflation than in the previous periods. We consider the Fed's responses until the late '90s reported in Clarida et al. (1999) [6] as an input in our monetary policy experiments. We further take an input from Kim and Pruitt (2017) [7], who consider the post-2008 period as well. This period is called the "zero lower bound" because central banks around the world set interest rates near zero, and thus become less responsive to inflation. Such a situation of "liquidity trap" makes the conventional interest rate instrument ineffective, and thus central banks resort to buying assets directly from the market. Quantitative easing steps can be found in Fawley and Neely (2013) [8].

\section{Literature}

The agent-based model literature is vast in both science and economics (an interesting primer is Chattoe-Brown 2013 [9]). In economics, agent behavior is not described in detail as in biology or the physics of particles, for example (Haldane and Turrel 2018) [10]. However, the assumptions of economic models are usually described in detail. Economic behavior is also more uncertain and, as a result, data are expected to fit a model only probabilistically. 
Interpreting results from an agent-based model requires a different perspective. One model has to be viewed as a device generating a number of alternative results, and this calls for devising several experiments or many realizations from a single model.

It is argued that dynamic factor models and machine learning are better suited for forecasting than agent-based models (Stock and Watson 2011 [11]; Chakraborty and Joseph 2017 [12]). However, agent-based models seem to be more adapted to tackle heterogeneity than DSGE models, for instance. While the DSGE makes a number of assumptions such as rational expectations, an agent-based model does not even offer a core model. This feature makes agent-based models more flexible to solve complex problems involving heterogeneous agents, who can make rational expectations or not. This flexibility explains its crescent use in economics. Yet one downside of flexibility is loss of analytical framing, which needs to be replaced by numerical convergence (Haldane and Turrel 2018) [10].

The agent-based model is better suited when the problem studied is a particular policy. In epidemiology, the model can be used to identify risk factors of a virus outbreak in a region and its spreading through other regions, though the model cannot predict a single state of outbreak in a particular period (Degli Atti et al. 2008) [13].

A canonical agent-based macroeconomic model is the EURACE (Cincotti et al. 2010 [14]; Deissenberg et al. 2008 [15]; Dawid et al. 2018 [16]). The macro model we present here builds on Delli Gatti et al. (2011) [17] and Assenza et al. (2015) [1], where $C$-firms produce final goods and use capital as an input that is exclusively produced by another set of firms-the $K$-firms. Both types of firms need workers, who they hire and fire at will. Workers receive wages and consume goods produced by the $C$-firms. (Delli Gatti and Desiderio 2015 [18] provide a review of agent-based models that consider monetary policy experiments.)

In Assenza et al.'s (2015) [1] model with capital and credit, firms demand heterogeneous capital to produce goods, and heterogeneous labor to produce either goods or capital. There are four categories of agents: households, $C$-firms, $K$-firms, and a bank. Though the series of GDP they compute fluctuates around a long-run mean, it can also endogenously manifest "crises." A crisis occurs whenever the unemployment rate hits and overshoots 15 percent. The GDP can plummet during a few periods while taking longer to recover. The model is able to replicate the real-world dynamics of crisis-whenever credit available to the firms shrunk, investment decreases, consumption drops, and real GDP and employment plunge.

As observed, we insert a central bank into Assenza et al.'s model and its behavior is modeled by Taylor's rule. Orphanides (2003) [19] employs Taylor's rule to describe the evolution of U.S. monetary policy since the 1920s, and finds a "surprising consistency." Clarida et al. (1999) [6] show Taylor's rule successfully fits monetary policy reaction functions over time for the postwar U.S. economy. 
This result seems to extend to the period after the 2008 financial crisis as well. Kim and Pruitt (2017) [7] find that Taylor's rule tracks the fact that the Fed's inflation response is significantly diminished after 2008, while response to unemployment is heightened. However, they find policy-response coefficients near zero in the zero-lower-bound environment, which may reflect the fact that the Fed then resorts to the unconventional policy of quantitative easing. (A comprehensive review of this related literature-including the literature on monetary policy—is already provided in Assenza et al. 2015 [1].)

\section{Model}

The model is medium size, with 3250 households divided between workers and entrepreneurs, 250 firms divided between $C$-firms and $K$-firms, two commercial banks (retail and wholesale), and a central bank. The model is written in NetLogo 6.0.1 and its code is available at the NetLogo library. Next, we briefly call attention to the extensions to the original model of Assenza et al. (2015) [1].

The model is composed of a consumer market, a capital market, a labor market and a credit market. The central bank receives input from the labor and consumption markets to decide, and this affects the financial sector (Figure 1).

\subsection{Setup}

Agents represent the minimal unit of behavior of the members of this economy; they are the players in the production, consumption and financial sectors.

Patches of a NetLogo grid are inhabited by only one firm per patch. There are as many patches as the number of firms. NetLogo sets 250 patches as a default.

Households can go through the patches freely. The position of the firms is constant during the experiments-they do not change their addresses. All the

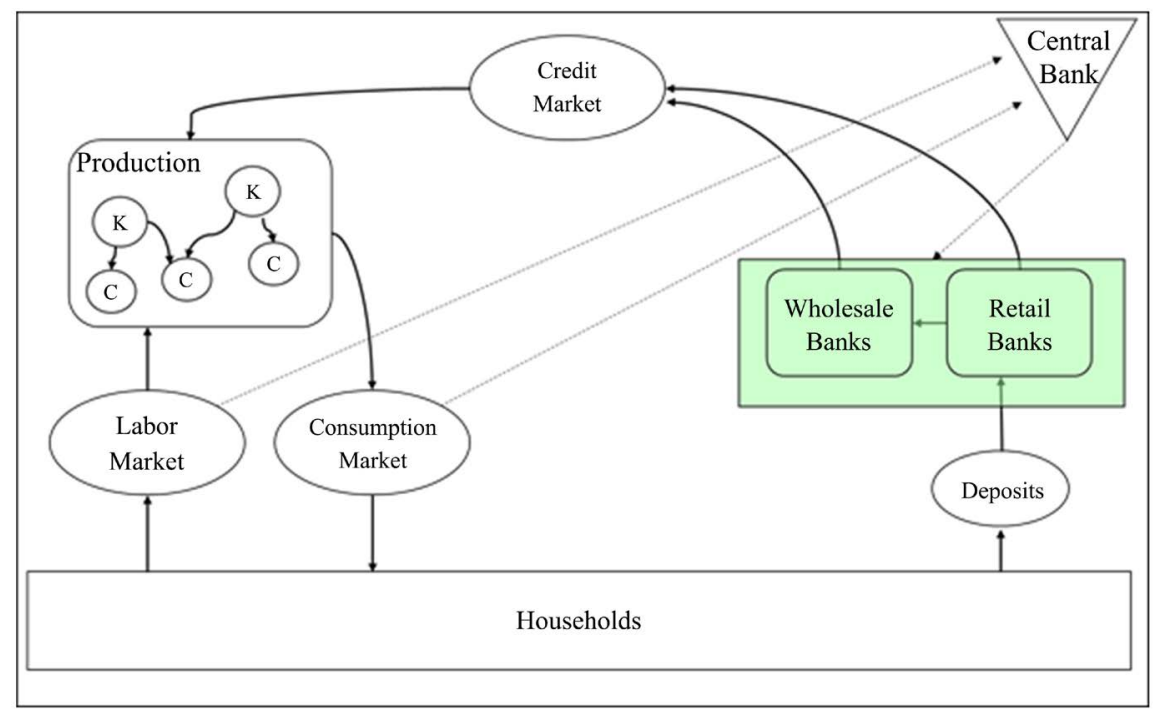

Figure 1. Agents and markets. The production sector is made up of $C$-firms and $K$-firms. The central bank observes unemployment from the labor market and inflation from the consumer market and then maps out the rules for the financial system. 
patches have the same characteristics. Every period represents a quarter and simulations can run for an arbitrary number of periods.

\subsection{Process and Scheduling}

Time is discrete and, each period, one firm chooses how much to produce and the price to charge. One household decides how much to consume and then deposits the sparing money in a retail bank.

Unemployed workers approach a restricted number of firms to find a job. Wages are constant and uniformly distributed across firms, so a worker accepts the first job offer. Workers are equally productive and thus firms hire those who first arrive.

Households are endowed with the amount of money they spend each period. One household approaches the $C$-firm of lowest price. If this firm does not have the good in stock, the household goes to the subsequent lower-price firm. If the stocks of all firms run out, the household saves the money.

$C$-firms combine labor and capital to produce goods. Capital and labor are employed in fixed proportion and there is no substitutability between them-a Leontief production function is assumed. One $C$-firm approaches $K$-firms to buy capital goods at the lowest price and so on, in a behavior similar to that of households in the consumer market.

Firms can borrow from banks. Banks with money available to lend charge an interest rate for these financial transactions on the basis of the base interest rate set by the central bank.

\subsection{Extensions}

To model a conventional monetary policy, we endogenize the interest rate of the original model by considering Taylor's rule:

$$
r_{t}=\pi_{t}+r^{*}+\alpha_{\pi}\left(\pi_{t}-\pi^{*}\right)+\alpha_{Y}\left(Y_{t}-\bar{Y}\right)
$$

where $r_{t}$ is the current base interest rate, $r^{*} \in(0,1)$ is the natural rate of interest, $\pi_{t}$ is the current inflation rate, $\pi^{*}$ is the target inflation rate, $Y_{t}$ is the current aggregate output (real GDP), $\bar{Y}$ is the potential output, and the central bank response parameters are $\alpha_{\pi} \in[0,2.5]$ and $\alpha_{Y} \in[0,1.3]$. This parameter configuration is calibrated from the U.S. monetary policy experience, as discussed in Section 5 and summarized in Table 5.

Quantitative easing is modeled by the rule:

$$
A_{C B, t}= \begin{cases}0, & \text { if } \frac{H_{u, t}}{H_{e, t}}<\psi \\ \chi, & \text { if } \frac{H_{u, t}}{H_{e, t}} \geq \psi\end{cases}
$$

where $A_{C B, t}$ is total private assets held by the central bank in period $t . H_{e, t}$ refers to employed workers in $t$ and $H_{u, t}$ stands for unemployed workers. Parameter $\psi$ is the unemployment rate considered as the threshold after which 
the central bank decides to purchase assets. In the policy experiments in Section 5, we consider $\psi$ as 4, 8, 10,12 and 14 percent (Table 8 and Table 9). Parameter $\chi$ refers to the quantity of private assets as a percentage of GDP. We set $\chi=20$ percent across the policy experiments, a value that is close to the mean of $\chi$ considering the experience of four major central banks (Tables 7-9).

\subsection{Initialization}

We start with $200 C$-firms and $50 K$-firms, and each occupies only one slot in the grid. Banks and the central bank inhabit arbitrary slots, and the grid has 250 patches as well. There are 250 entrepreneurs, each initially linked to one unique firm. And there are 3000 workers.

\section{Checking for Robustness}

We employ the protocol TRACE (TRAnsparent and Comprehensive model Evaluation) as in Schmolke et al. (2010) [20], Grimm et al. (2014) [21] and Muller et al. (2013) [22] to assess the internal logic consistency of our model. TRACE provides a check list that contemporaneously evaluates robustness during the process of building up a model. Whenever a new sub model is inserted into the code or novel results emerge from a new set of parameters, TRACE scrutinizes the process. Here, we highlight 1) a comparison of actual business cycle properties with those of our model, and 2) a checking of whether the simulated time series can reproduce stylized facts of the interbank market.

\subsection{Fitting actual Business Cycles}

We take U.S. real GDP, investment, consumption and unemployment quarterly data from 1955 to 2015 from the FRED database and apply the HP filter to detrend every series. Table 1 displays the cyclical components. Though our model cannot initially fit the high first lag autocorrelation of real GDP, it fairly succeeds after all sub models are included (Table 2). Moreover, crises endogenously emerge as more sub models are inserted. Row 3 in Table 2 shows that crises crop up after insertion of the interest rate routine.

Table 3 shows the cyclical components after inclusion of the conventional monetary policy sub model. The periods considered are taken from Clarida et al. (1999) [6] and Kim and Pruitt (2017) [7]. Table 4 shows the cyclical components

Table 1. Cyclical components of major macro variables: U.S. quarterly data from 1955 to 2015.

\begin{tabular}{ccc}
\hline Actual series & Standard deviation & First-lag autocorrelation function \\
\hline Real GDP & 2.22 & 0.798 \\
Investment & 11.32 & 0.738 \\
Consumption & 1.68 & 0.747 \\
Unemployment rate & 16.81 & 0.842 \\
\hline
\end{tabular}

Source: FRED. 
Table 2. Robustness check after step-by-step inclusion of a sub model.

\begin{tabular}{ccc}
\hline Modeling step & Crisis? & GDP's first-lag autocorrelation function \\
\hline Price decision & No & 0.259 \\
Retail bank & No & 0.350 \\
Interest rate routine & Yes & 0.634 \\
Interbank market & Yes & 0.613 \\
\hline
\end{tabular}

Note: Crisis refers to the unemployment rate hitting and overshooting 15 percent.

Table 3. Cyclical components of the simulated time series after inclusion of the conventional monetary policy routine.

\begin{tabular}{ccccccccc}
\hline \multirow{2}{*}{ Experiment } & \multicolumn{2}{c}{ GDP } & \multicolumn{2}{c}{ Investment } & \multicolumn{2}{c}{ Consumption } & \multicolumn{2}{c}{ Unemployment } \\
\cline { 2 - 8 } & S.D. & ACF & S.D. & ACF & S.D. & ACF & S.D. & ACF \\
\hline Pre-Volcker & 1.57 & 0.58 & 29.0 & 0.37 & 1.04 & 0.08 & 34.4 & 0.35 \\
Volcker-Greenspan & 1.58 & 0.56 & 22.6 & 0.24 & 1.00 & 0.12 & 35.5 & 0.36 \\
Post-1982 & 1.72 & 0.58 & 21.3 & 0.33 & 0.99 & 0.10 & 35.8 & 0.31 \\
Post-2008 & 1.51 & 0.57 & 25.2 & 0.37 & 0.99 & 0.15 & 34.8 & 0.35 \\
\hline
\end{tabular}

Note: Periods in our Taylor's rule experiment match those from several Fed eras and may overlap. Standard deviations (S.D.) and first-lag autocorrelation functions (ACF) are the average over 10 periods of 2500 runs each, where only the last 2000 runs are considered.

Table 4. Cyclical components of the simulated time series after inclusion of the quantitative easing policy routine.

\begin{tabular}{ccccccccc}
\hline \multirow{2}{*}{ Experiment } & \multicolumn{2}{c}{ GDP } & \multicolumn{2}{c}{ Investment } & \multicolumn{2}{c}{ Consumption } & \multicolumn{2}{c}{ Unemployment } \\
\cline { 2 - 8 } & S.D. & ACF & S.D. & ACF & S.D. & ACF & S.D. & ACF \\
\hline First policy & 2.61 & 0.66 & 12.5 & 0.50 & 1.20 & 0.35 & 19.2 & 0.40 \\
Second policy & 2.76 & 0.64 & 14.5 & 0.46 & 1.21 & 0.36 & 22.1 & 0.37 \\
Third policy & 2.97 & 0.65 & 15.3 & 0.49 & 1.15 & 0.37 & 23.0 & 0.36 \\
Fourth policy & 2.39 & 0.64 & 11.7 & 0.42 & 1.17 & 0.39 & 22.3 & 0.42 \\
\hline
\end{tabular}

Note: Standard deviations and first-lag autocorrelation functions are the average over 10 periods of 2500 runs each, where only the last 2000 runs are considered.

after inclusion of the quantitative easing policy routine. Both modeling steps pass the robustness check.

\subsection{Fitting Actual Interbank Markets}

Interbank market dynamics is central in a financial crisis as observed, and some even blamed the wholesale banks for the last 2008 crisis (Gertler et al. 2016 [2]; Curdia and Woodford 2010 [23]). Figure 2 shows total credit supplied by banks to firms and GDP behavior in our model. The role played by wholesale bank loans is key. The dynamics of credit availability to firms from wholesale banks emerges as a result of the liquidity of the interbank market, as wholesale banks depend on retail bank cash to supply the system. In turn, the $C$-firms need credit 
to invest and if credit is unavailable to them, their purchases of capital goods from the $K$-firms are reduced. As a result, both types of firm fire workers and GDP plummets. Because wholesale banks offer low installment debt rates, firms prefer to borrow from them. These very wholesale bank loans exhibit the highest impact in our simulations, being ultimately responsible for crises.

Moreover, Figure 3 shows our model can replicate the business cycle fact that the 2008 crisis was preceded by a credit crunch that began one year earlier.

\section{Policy Experiments}

\subsection{Conventional Monetary Policy}

Table 5 shows the Taylor's rule parameter values $\alpha_{\pi}$ and $\alpha_{Y}$ employed in our experiments. For the post-2008 experiment, the values are taken from Kim

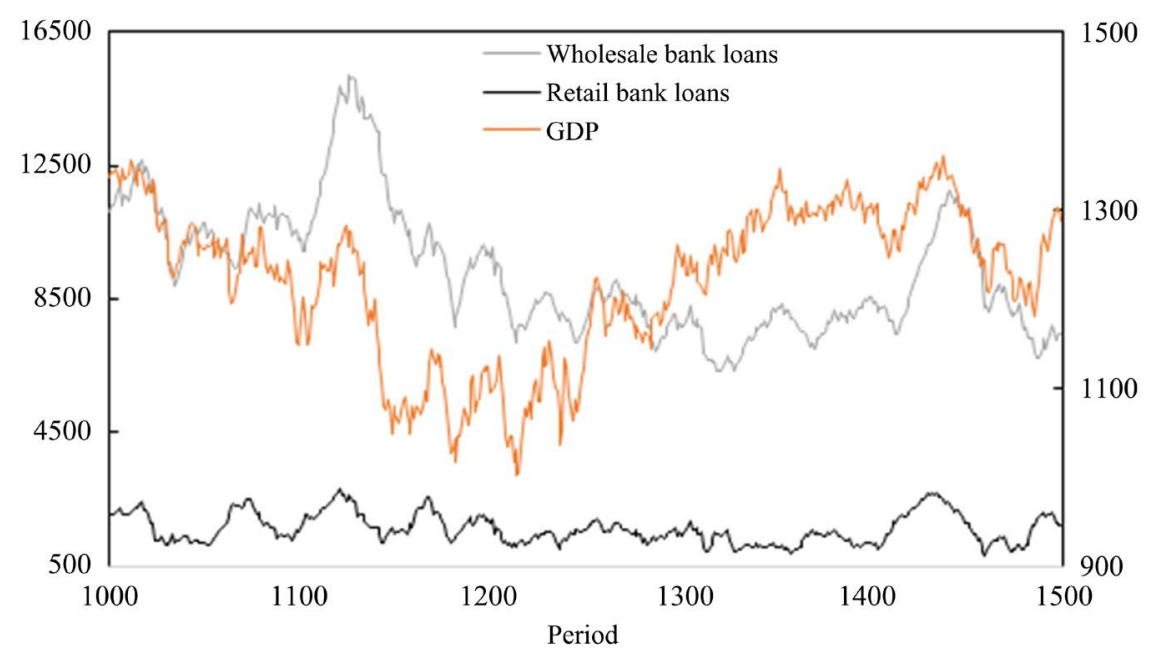

Figure 2. The total credit supplied by banks to firms (left vertical axis) and GDP behavior (right vertical axis).

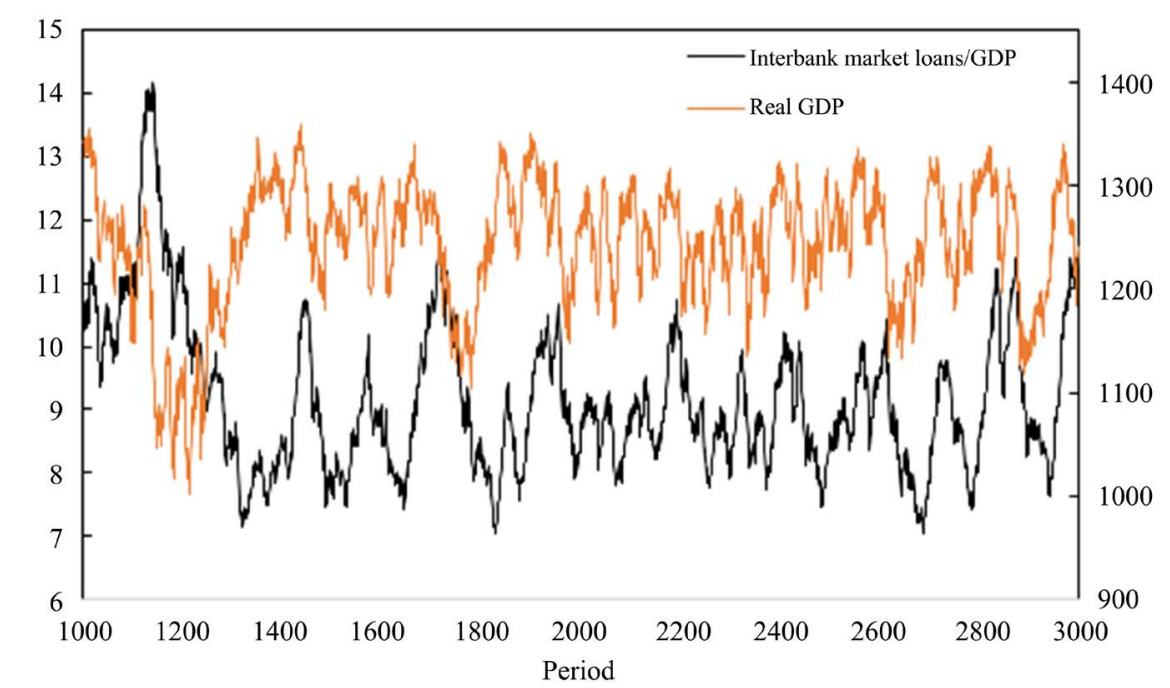

Figure 3. The interbank market loans (left vertical axis) and GDP behavior (right vertical axis) in one single simulation of our model. 
Table 5. Taylor's rule parameter values considered in the conventional monetary policy experiments.

\begin{tabular}{ccc}
\hline Experiment & $\alpha_{\pi}$ & $\alpha_{\mathrm{Y}}$ \\
\hline Pre-Volcker & 0.86 & 0.39 \\
Volcker-Greenspan & 1.72 & 0.34 \\
Post-1982 & 2.55 & 0.00 \\
Post-2008 & 0.00 & 1.30 \\
\hline
\end{tabular}

Source: Clarida et al. (1999) [6] and Kim and Pruitt (2017) [7].

and Pruitt (2017) [7], while all the others are from Clarida et al. (1999) [6]. As in Assenza et al. (2015) [1], the model is run 10 times for 2500 periods and then the output is recorded. This seems rather small regarding significance, and it is also ad hoc because one needs systematic procedures in the design of experiments. Nevertheless, we decide to consider the second-best alternative of following the modus operandi in Assenza et al.

Table 6 shows the occurrence of crises per simulation across the conventional monetary policy experiments. Crises are more common in the post-1982 experiment.

Figure 4 illustrates sample simulations for every experiment. Crises occur whenever the unemployment rate is $\geq 15$ percent. (For the highlighted areas of the unemployment rate series in Figure 4, the reader is invited to experiment with the NetLogo model to check that the GDP, consumption and investment series show consistent patterns.)

\subsection{Quantitative Easing}

Quantitative easing became a common policy after the 2008 crisis. For more than six years, the Fed administered round after round of quantitative easing, and only in recent years decided to scale back its operations. Central bank purchases of private assets directly from the banks was the favorite practice (Fawley and Neely 2013) [8]. Table 7 shows total purchases as a percentage of real GDP for major central banks. In our quantitative easing experiments, we choose $\chi$ $=20$ percent. Considering the values in Table 7 , this is a conservative limit. Thus, we make our case that quantitative easing outperforms the conventional policies parsimoniously.

Quantitative easing is not adopted continuously. Central banks resort to them only when the unemployment rate overshoots some threshold and the conventional policies show signs of not working. Our experiments do the same. We pick four trigger values related to the unemployment rate, $\psi$, for the central bank to start to intervene using quantitative easing. These define four policies, as described in Table 8.

Again, the model is run 10 times for every policy, each simulation has 2500 periods, and output is collected at the end. As before, a crisis emerges whenever the unemployment rate hits and overshoots 15 percent (Table 9). Compared 
Table 6. Crises across the conventional monetary policy experiments.

\begin{tabular}{cccc}
\hline Experiment & $\alpha_{\pi}$ & $\alpha_{\mathrm{Y}}$ & Mean number of crises \\
\hline Pre-Volcker & 0.86 & 0.39 & $52( \pm 29)$ \\
Volcker-Greenspan & 1.72 & 0.34 & $30( \pm 11)$ \\
Post-1982 & 2.55 & 0.00 & $86( \pm 37)$ \\
Post-2008 & 0.00 & 1.30 & $10( \pm 6)$ \\
Total mean & & & 44 \\
\hline
\end{tabular}

Note: Crisis refers to the unemployment rate hitting and overshooting 15 percent.

Table 7. Total private assets held by central banks as a percentage of real GDP.

\begin{tabular}{ccc}
\hline Central bank & Percentage of GDP & \\
\hline Fed & 22.1 & 27 \\
BoE & 26.3 & 30 \\
ECB & 3.5 & 28 \\
BoJ & 37.5 & 104 \\
Mean & 22.3 & 47.2 \\
\hline
\end{tabular}

Note: The second column refers to data as of February 2013, and the third column shows data as of August 2020. Source: Fawley and Neely (2013) [8] and Bailey et al. (2020) [24].

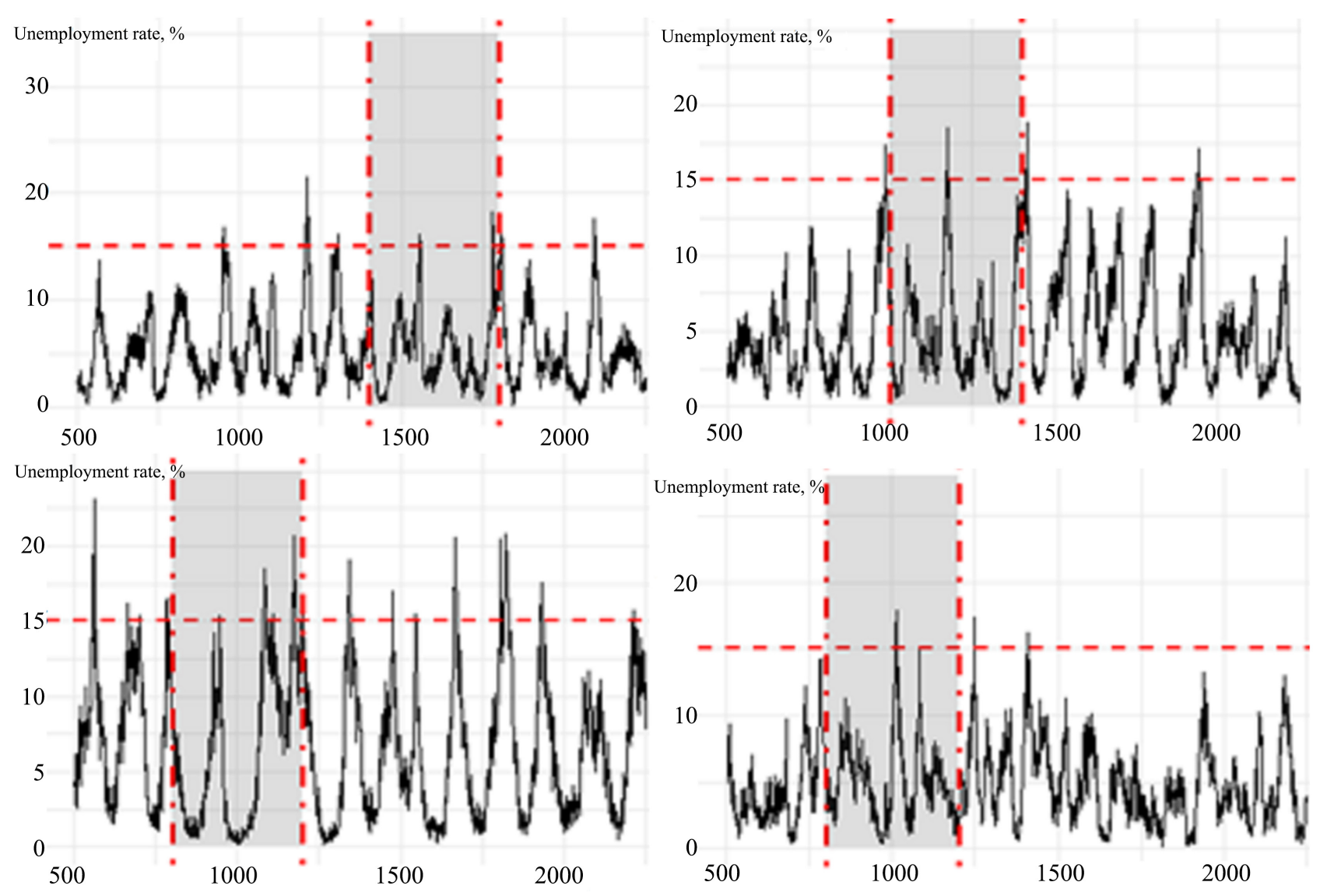

Figure 4. Crises emerging in the conventional monetary policy experiments. From top left to bottom right, pre-Volcker, Volcker-Greenspan, post-1982 and post-2008 periods. 
Table 8. Quantitative easing policy experiments.

\begin{tabular}{ccc}
\hline Experiment & $\psi, \%$ & $\chi, \%$ \\
\hline First policy & 8 & 20 \\
Second policy & 10 & 20 \\
Third policy & 12 & 20 \\
Fourth policy & 14 & 20 \\
\hline
\end{tabular}

Table 9. Crises across the quantitative easing monetary policy experiments.

\begin{tabular}{cccc}
\hline Experiment & $\psi, \%$ & $\chi, \%$ & Mean number of crises \\
\hline First policy & 8 & 20 & $0(0)$ \\
Second policy & 10 & 20 & $1( \pm 1)$ \\
Third policy & 12 & 20 & $2( \pm 2)$ \\
Fourth policy & 14 & 20 & $7( \pm 3)$ \\
Total mean & & & 4.75 \\
\hline
\end{tabular}

Table 10. The unemployment rate across all the monetary policy experiments: mean, standard deviation, excess kurtosis, maximum and quartiles.

\begin{tabular}{ccccccccc}
\hline Experiment & Period & Mean & S.D. & Kurtosis & Max & $25 \%$ & $50 \%$ & $75 \%$ \\
\hline Pre-Volcker & 20,000 & 0.050 & 0.038 & 3.072 & 0.274 & 0.022 & 0.040 & 0.069 \\
Volcker-Greenspan & 20,000 & 0.048 & 0.035 & 3.100 & 0.288 & 0.021 & 0.039 & 0.065 \\
Post-1982 & 20,000 & 0.056 & 0.047 & 4.550 & 0.439 & 0.022 & 0.042 & 0.075 \\
Post-2008 & 20,000 & 0.045 & 0.029 & 3.185 & 0.201 & 0.023 & 0.039 & 0.061 \\
First policy & 20,000 & 0.046 & 0.022 & 1.686 & 0.139 & 0.028 & 0.045 & 0.063 \\
Second policy & 20,000 & 0.047 & 0.025 & 2.036 & 0.165 & 0.028 & 0.044 & 0.065 \\
Third policy & 20,000 & 0.049 & 0.028 & 2.296 & 0.154 & 0.026 & 0.043 & 0.066 \\
Fourth policy & 20,000 & 0.048 & 0.029 & 2.679 & 0.183 & 0.026 & 0.041 & 0.063 \\
\hline
\end{tabular}

with Table 6, crises are less frequent under quantitative easing. Table 9 also shows that the earlier the central bank intervenes-when the unemployment rate is still relatively low at 8 percent-the less the crises crop up. The first policy is even capable of preventing crises altogether. Figure 5 illustrates sample simulations for every experiment, and Table 10 shows that quantitative easing has an edge over Taylor's rule-style policies to tame unemployment (average S.D. = 0.026 for quantitative easing and average S.D. $=0.037$ for the conventional policies; excess kurtosis $<3$ for all the quantitative easing policies).

Many feared that the Fed's policies of quantitative easing would lead to hyperinflation. However, there was only a very modest inflation increase. This occurred because a spike in the M0 monetary base was mostly retained by the financial sector and the M2 money supply remained fairly stable. As in the basic model, in our extended model consumer goods prices cannot exhibit excessive inflation because the wages paid are fixed. We leave for future research relaxing 


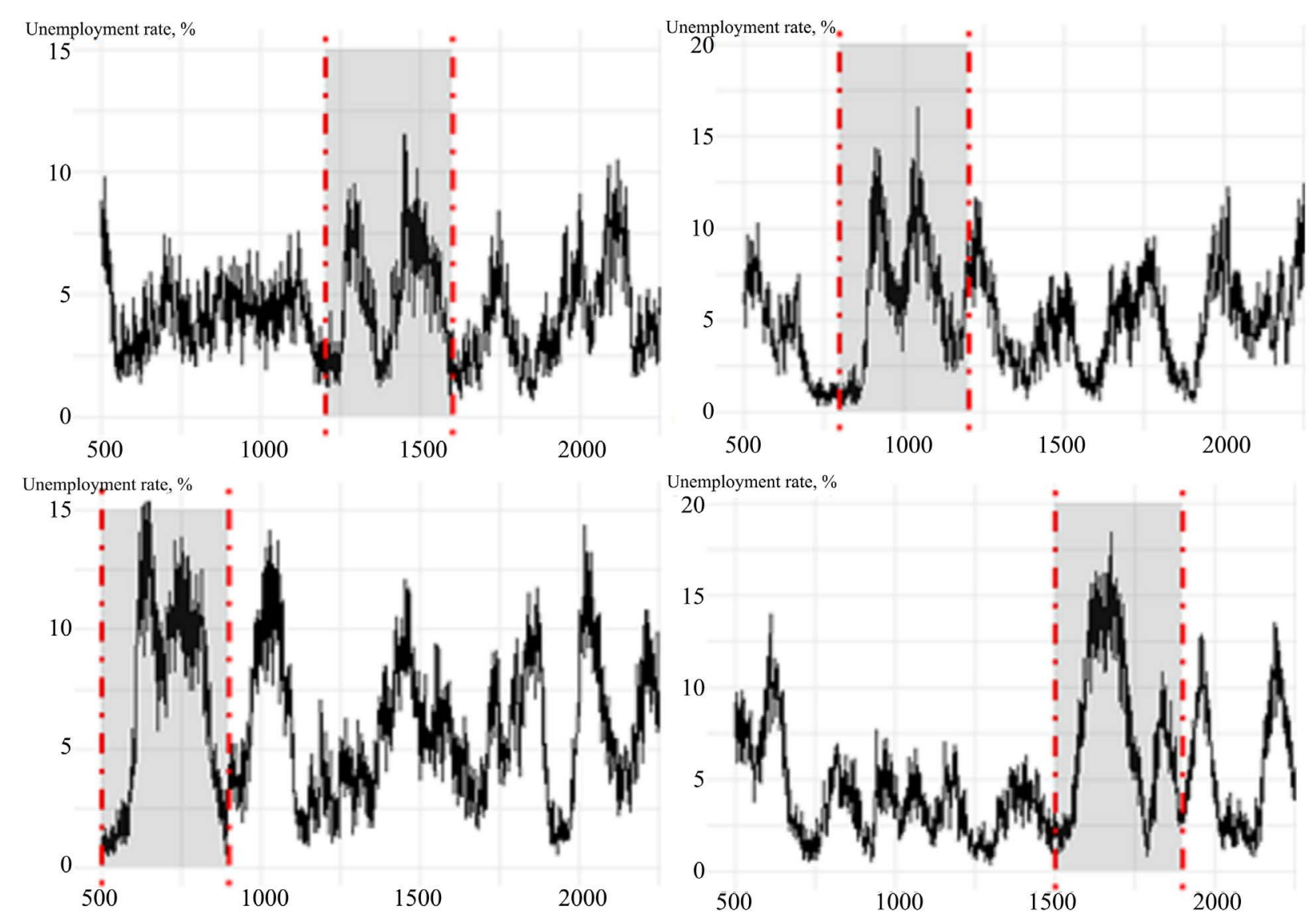

Figure 5. Portion of data for the four experiments of quantitative easing. Crises are absent in the first experiment (top left), where the unemployment rate does not reach 15 percent.

this hypothesis, thus making it possible to consider the possibility of hyperinflation in quantitative easing by increasing $\psi$ beyond 14 percent.

\section{Conclusions}

This paper employs an agent-based macroeconomic model with capital and credit that explicitly considers an interbank market and a central bank. Our goal is to pit conventional and unconventional monetary policies against each other. We take eight experiments related to four conventional policies and four quantitative easing policies.

One practical feature of our agent-based macroeconomic model is to be able to consider any type of monetary policy, conventional or not, inside a single framework. By comparing Taylor's rule-style policies with quantitative easing, we find the superiority of quantitative easing in reducing the volatility of business cycle fluctuations. Crises are less frequent under quantitative easing and the earlier a central bank intervenes, the less the crises crop up. At the limit, crises can even vanish in the model.

\section{Funding}

Financial support from CNPq and Capes is acknowledged. 


\section{Conflicts of Interest}

The authors declare that there is no conflict of interest.

\section{References}

[1] Assenza, T., Delli Gatti, D. and Grazzini, J. (2015) Emergent Dynamics of a Macroeconomic Agent Based Model with Capital and Credit. Journal of Economic Dynamics and Control, 50, 5-28. https://doi.org/10.1016/j.jedc.2014.07.001

[2] Gertler, M., Kiyotaki, N. and Prestipino, A. (2016) Wholesale Banking and Bank Runs in Macroeconomic Modelling of Financial Crises. In: Taylor, J.B. and Uhlig, H., Eds., Handbook of Macroeconomics, Volume 2, Elsevier, Amsterdam, 1345-1425. https://doi.org/10.3386/w21892

[3] Bernanke, B. and Gertler, M. (1989) Agency Costs, Net Worth, and Business Fluctuations. American Economic Review, 79, 14-31.

[4] Kiyotaki, N. and Moore, J. (1997) Credit Cycles. Journal of Political Economy, 105, 211-248. https://doi.org/10.1086/262072

[5] Taylor, J.B. (1993) Discretion versus Policy Rules in Practice. Carnegie-Rochester Conference Series on Public Policy, 39, 195-214.

https://doi.org/10.1016/0167-2231(93)90009-L

[6] Clarida, R.G., Gali, J. and Gertler, M. (1999) The Science of Monetary Policy: A New Keynesian Perspective. Journal of Economic Literature, 37, 1661-1707. https://doi.org/10.1257/jel.37.4.1661

[7] Kim, J. and Pruitt, S. (2017) Estimating Monetary Policy Rules When Nominal Interest Rates Are Stuck at Zero. Journal of Money, Credit and Banking, 49, 585-602. https://doi.org/10.1111/jmcb.12391

[8] Fawley, B.W. and Neely, C.J. (2013) Four Stories of Quantitative Easing. Federal Reserve Bank of St. Louis, 95, 51-88. https://doi.org/10.20955/r.95.51-88

[9] Chattoe-Brown, E. (2013) Why Sociology Should Use Agent Based Modelling. Sociological Research Online, 18, 31-41. https://doi.org/10.5153/sro.3055

[10] Haldane, A.G. and Turrell, A.E. (2018) An Interdisciplinary Model for Macroeconomics. Oxford Review of Economic Policy, 34, 219-251. https://doi.org/10.1093/oxrep/grx051

[11] Stock, J.H. and Watson, M.W. (2011) Dynamic Factor Models. In: Clements, M.J. and Hendry, D.F., Eds., Oxford Handbook on Economic Forecasting, Oxford University Press, Oxford, 35-59.

[12] Chakraborty, C. and Joseph, A. (2017) Machine Learning at Central Banks. Bank of England Staff Working Paper No. 674. https://doi.org/10.2139/ssrn.3031796

[13] Degli Atti, M.L.C., Merler, S., Rizzo, C., Ajelli, M., Massari, M., Manfredi, P., Furlanello, C., Tomba, G.S. and Iannelli, M. (2008) Mitigation Measures for Pandemic Influenza in Italy: An Individual Based Model Considering Different Scenarios. PLoS ONE, 3, e1790. https://doi.org/10.1371/journal.pone.0001790

[14] Cincotti, S., Raberto, M. and Teglio, A. (2010) Credit Money and Macroeconomic Instability in the Agent-Based Model and Simulator EURACE. Economics, 4, 1-32. https://doi.org/10.5018/economics-ejournal.ja.2010-26

[15] Deissenberg, C., van der Hoog, S. and Dawid, H. (2008) EURACE: A Massively Parallel Agent-Based Model of the European Economy. Applied Mathematics and Computation, 204, 541-552. https://doi.org/10.1016/j.amc.2008.05.116

[16] Dawid, H., Gemkow, S., Harting, P., van der Hoog, S. and Neugart, M. (2018) 
Agent-Based Macroeconomic Modeling and Policy Analysis: The Eurace@Unibi Model. In: Chen, S.H., Kaboudan, M. and Du, Y.R., Eds., The Oxford Handbook of Computational Economics and Finance, Oxford University Press, New York, 490-519.

[17] Delli Gatti, D., Desiderio, S., Gaffeo, E., Cirillo, P. and Gallegati, M. (2011) Macroeconomics from the Bottom-Up. Springer, Milan.

https://doi.org/10.1007/978-88-470-1971-3

[18] Delli Gatti, D. and Desiderio, S. (2015) Monetary Policy Experiments in an Agent-Based Model with Financial Frictions. Journal of Economic Interaction and Coordination, 10, 265-286. https://doi.org/10.1007/s11403-014-0123-7

[19] Orphanides, A. (2003) Historical Monetary Policy Analysis and the Taylor Rule. Journal of Monetary Economics, 50, 983-1022.

https://doi.org/10.1016/S0304-3932(03)00065-5

[20] Schmolke, A., Thorbek, P., DeAngelis, D.L. and Grimm, V. (2010) Ecological Models Supporting Environmental Decision Making: A Strategy for the Future. Trends in Ecology \& Evolution, 25, 479-486. https://doi.org/10.1016/j.tree.2010.05.001

[21] Grimm, V., Augusiak, J., Focks, A., Frank, B.M., Gabsi, F., Johnston, A.S.A., Liu, C., Martin, B.T., Meli, M., Radchuk, V., Thorbek, P. and Railsback, S.F. (2014) Towards Better Modelling and Decision Support: Documenting Model Development, Testing, and Analysis Using TRACE. Ecological Modelling, 280, 129-139. https://doi.org/10.1016/j.ecolmodel.2014.01.018

[22] Muller, B., Bohn, F., Drebler, G., Groeneveld, J., Klassert, C., Martin, R., Schlüter, M., Schulze, J., Weise, H. and Schwarz, N. (2013) Describing Human Decisions in Agent-Based Models-ODD + D, an Extension of the ODD Protocol. Environmental Modelling \& Software, 48, 37-48. https://doi.org/10.1016/j.envsoft.2013.06.003

[23] Curdia, V. and Woodford, M. (2010) Credit Spreads and Monetary Policy. Journal of Money, Credit and Banking, 42, 3-35. https://doi.org/10.1111/j.1538-4616.2010.00328.x

[24] Bailey, A., Bridges, J., Harrison, R., Jones, J. and Mankodi, A. (2020) The Central Bank Balance Sheet as a Policy Tool: Past, Present and Future. Bank of England, London. https://doi.org/10.2139/ssrn.3753734 https://www.bankofengland.co.uk/-/media/boe/files/paper/2020/the-central-bank-b alance-sheet-as-a-policy-tool-past-present-and-future.pdf 